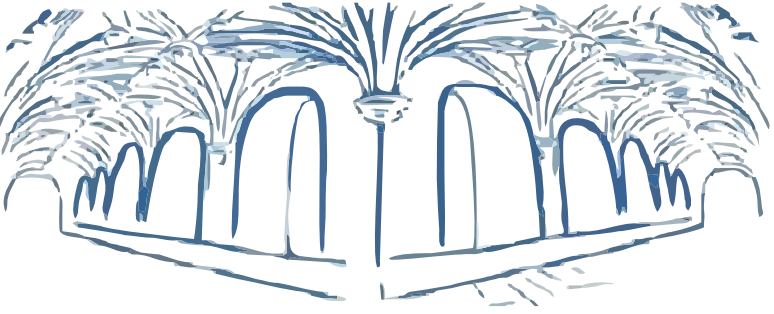

Ferreira, A. S., Teixeira, D., Marta, M. \& Araújo, S. B. (2021). Prática educativa supervisionada em creche: Uma Experiência pikleriana em contexto português.

Revista Practicum, 6(1), 59-74.

https://doi.org/10.24310/RevPracticumrep.v6i1.10194

\section{R E V I S T A PRACTICUM}

Número 6(1), Enero-Junio, 2021 ISSN: $2530-4550$

\title{
Prática educativa supervisionada em creche: Uma experiência pikleriana em contexto português
}

\section{Supervised educational practice in daycare: A piklerian experience in a portuguese context}

\author{
Ana Sabrina Ferreira \\ Escola Superior de Educação do Politécnico do Porto \\ asabrinaferreira@gmail.com \\ Diana Teixeira \\ Escola Superior de Educação do Politécnico do Porto \\ dianamteixeira@hotmail.com \\ Margarida Marta \\ Escola Superior de Educação do Politécnico do Porto \\ margaridamarta@ese.ipp.pt \\ Sara Barros Araújo \\ Escola Superior de Educação do Politécnico do Porto \\ saraujo@ese.ipp.pt
}

\section{Resumo}

A creche é um contexto educativo onde se devem criar oportunidades de aprendizagem significativas na vida de bebés e crianças. Este artigo pretende dar ênfase a uma perspetiva pedagógica para a educação em creche, a perspetiva de Emmi Pikler, e ao seu contributo em processos formativos no âmbito da prática educativa supervisionada de um mestrado profissionalizante, em contexto português. Tem como objetivo descrever e analisar a experimentação do Triân- 
gulo de Pikler no âmbito de um estágio desenvolvido em contexto de creche, com atenção simultânea aos efeitos desta proposta pedagógica na experiência das crianças e na aprendizagem profissional de educadoras estagiárias. Relativamente à primeira, são de destacar efeitos positivos ao nível da autonomia, interações e experiência emocional das crianças, enquanto, relativamente à segunda, salienta-se o contributo formativo no âmbito da observação contextualizada e participante, sensível e atenta, e da tomada de consciência das particularidades da ação profissional com crianças mais novas, sobretudo ao nível do papel do adulto.

\section{Abstract}

The daycare center is an educational context where significant learning opportunities must be created in the lives of babies and children. This article intends to emphasize an educational perspective for daycare education, the perspective of Emmi Pikler, and its contribution in training processes within the supervised educational practice of a professionalizing master's degree, in the Portuguese context. It aims to describe and analyze the experimentation of the Pikler Triangle in the context of a practicum developed in a daycare center, with simultaneous attention to the effects of this pedagogical proposal on children's experience and on the professional learning of the students. With regard to the first, there are positive effects in terms of children's autonomy, interactions and emotional experience, while in relation to the second, the formative contribution is highlighted at the level of a contextualized, participative, sensitive and attentive observation, and by an awareness about the particularities of professional action with younger children, especially in what concerns the adult's role.

\section{Palavras - chave}

Creche, Triângulo de Pikler, Estágio, Formação profissionalizante.

\section{Keywords}

Daycare, Pikler Triangle, Practicum, Professional training.

\section{Introdução}

A abordagem Pikler-Lóczy assume-se como uma proposta pedagógica específica para a primeira infância que foi desenvolvida por Emmi Pikler e a sua equipa do Instituto Lóczy desde 1946, quando esta assumiu a direção deste instituto, um centro de acolhimento de crianças órfãs (David \& Appell, 2010).

Na sua perspetiva pedagógica, Pikler rompe com a conceção tradicional de criança como um ser passivo e sem direitos, entendendo antes "o bebé como 
um sujeito ativo, (...) que atua nos espaços, com os materiais, nas interações com os outros bebés e adultos" (Fochi, 2018, p. 186). Pikler defende que "a criança tem um projeto de desenvolvimento próprio, criado por ela mesma, e que se vai configurando em relação com o ambiente envolvente e as leis biológicas do seu organismo" (Godall, 2016, p. 91), numa interação ecológica que permite reconhecer as suas potencialidades e os seus ritmos de desenvolvimento. Assim, de modo a que a ação da criança adquira significado é essencial que esta surja da sua própria iniciativa e que seja reconhecida como ativa, participativa e colaborativa (Falk, 2012). A perspetiva pikleriana dá ênfase à forma como o adulto reconhece a criança, considerando-a como "companheira na relação e uma interlocutora no diálogo" (Araújo, 2017, p. 105). Esta relação promove, desde o nascimento, a liberdade, a autonomia e a competência motora que são vividas e partilhadas numa criação de vínculo estável e afetivo.

Uma das maiores contribuições desta perspetiva pedagógica prende-se, então, com a conceção de criança competente que se desenvolve em estreita relação e comunicação com um ambiente envolvente favorável, conferindo, assim, um significado diferente ao termo competência (Godall, 2016). De acordo com Godall (2016), Emmi Pikler reconhece e utiliza a expressão sentimento de competência com verdadeiro significado, uma vez que compreende a relação entre essa expressão e os "movimentos ativos do ser humano desde o nascimento" (p. 91). Não obstante, perspetiva a importância de o adulto responsável não se abster na atividade da criança, mas sim estar presente e ser apoiante e estimulador da sua atividade motora de forma indireta, através de olhares e comentários realizados à distância, reconhecendo as suas conquistas e transmitindo um sentimento de confiança (David \& Appell, 2010; Fochi, 2018), de tranquilidade, sem necessitar, algumas vezes, de proferir qualquer palavra.

Também conhecida como a Pedagogia dos Detalhes, valoriza as crianças na sua condição humana, dando especial atenção às características singulares de cada criança e ao modo de agir do/a educador/a de infância numa interação e experimentação que representam múltiplas formas de brincar ao explorar, ao sentir, ao trocar olhares e sorrisos (David \& Appell, 2010; Fochi, 2018).

Os princípios e valores na base desta pedagogia apoiam-se na ideia de criança competente e capaz, ou seja, na criança com agência, e são fundamentalmente quatro: (i) a valorização da atividade autônoma; (ii) a importância de uma relação afetiva de qualidade entre adulto e criança; (iii) a necessidade de promover a tomada de consciência pela criança de si mesma e da sua interação com o contexto; e (iv) a importância de um bom estado de saúde (David \& Appell, 2010).

No que respeita às opções pedagógicas, que inspiram os diferentes formatos de organização, estas devem favorecer a autonomia e o jogo livre da criança, sendo as situações de atividade autónoma "momentos que exigem uma preparação 
segundo objetivos específicos e que constituem motivo de reflexão, planificação e de modificação constantes" (David \& Appell, 2010, p. 55). O espaço e materiais são configurados para proporcionar atividades sensoriais, visando desenvolver os cinco sentidos, a coordenação motora, a atenção, a concentração e a criatividade, despertando prazer e aprendizagem.

As primeiras interações dos bebés e crianças mais novas ocorrem com os adultos que deles/as cuidam. Neste sentido, e tendo em conta a visão de criança enquanto sujeito ativo na abordagem pikleriana, é fácil entender que deve ser o bebé a atuar nos espaços, quer na relação estabelecida com os materiais, quer nas interações com os outros bebés e adultos que o rodeiam, sempre sob o olhar atento do adulto numa relação de reciprocidade (Kálló \& Vámos, 2014), de proximidade, de alegria, mas não de invasão do seu tempo, do seu espaço e da sua ação (Fochi, 2018).

Os ambientes educativos devem oferecer objetos promotores do brincar que possibilitem o envolvimento em diversas explorações e experimentações por parte da criança, fazendo com que esta se sinta curiosa face ao que observa, seja capaz de atingir o que pretende e que se encontra ao seu alcance numa descoberta de si, do outro e do mundo. O objetivo não é que o adulto ofereça um estímulo específico com a intenção de criar aprendizagem, mas sim que organize o ambiente e que se envolva neste, pois, segundo Pikler, a criança desenvolvese de forma natural em relação com o ambiente e as aprendizagens emergem quando existe espaço suficiente para explorar livre e autonomamente (Godall, 2016; Tardos \& Appell, 2013). A importância do jogo livre torna-se, então, evidente, uma vez que este concentra em si a possibilidade de a criança propor a si própria a realização de uma tarefa, bem como de descobrir por si se a tarefa se demonstrou demasiado difícil e quais as estratégias possíveis a adotar para a realizar (Szoke, 2016).

Pelo exposto, o espaço e os materiais representam uma função crucial no desenvolvimento da criança no ambiente pikleriano, sendo que o espaço deve possibilitar à criança um certo nível de controlo, de forma a que esta se sinta segura para explorar livremente; deve proporcionar interações positivas e deve ser seguro e permitir a ação livre do bebé, "libertando-o não apenas de acidentes, mas de proibições ativas por parte do adulto, as quais inibiriam ou falseariam o seu movimento espontâneo para a ação e experimentação" (David \& Appell, 2010, p. 57).

Neste sentido, remete-se para a importância que o Triângulo de Pikler, um equipamento desenvolvido pela abordagem Pikler-Lóczy, poderá ter ao nível da exploração autónoma e movimento livre, respeitando, assim, os princípios basilares desta proposta pedagógica. Este equipamento é construído com material de origem natural - a madeira - e consiste numa estrutura triangular, com de- 


\section{PRACTICUM}

graus cilíndricos, assumindo assim uma configuração de escada, sendo possível ainda a adição de acessórios como uma rampa de madeira.

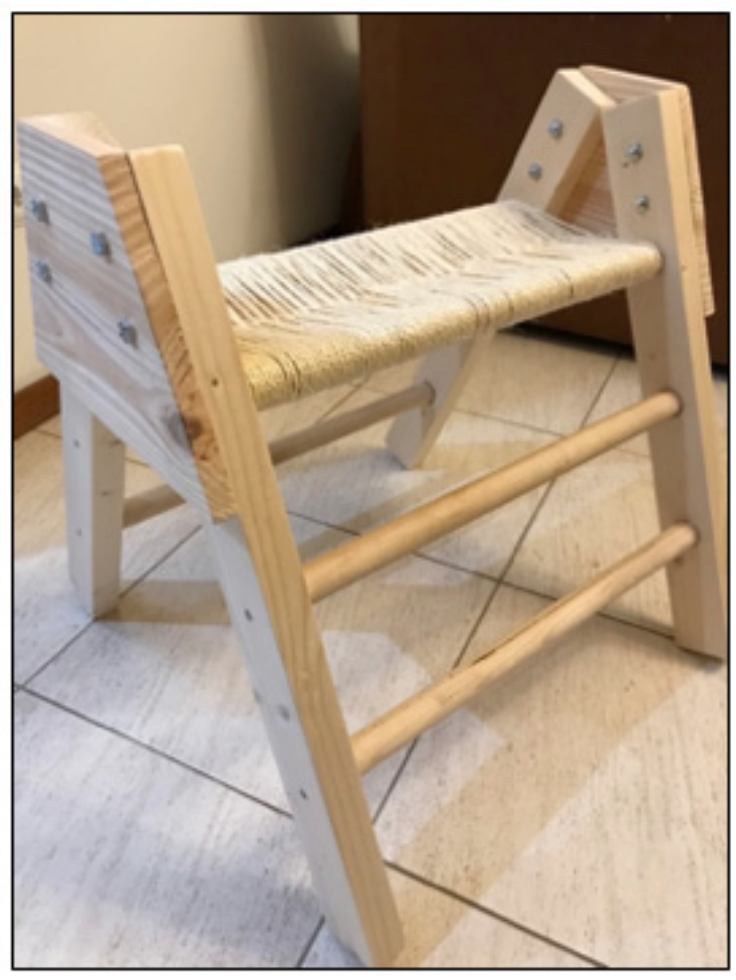

Figura 1 - Perspetiva frontal do Triângulo de Pikler. Fonte: elaboração própria

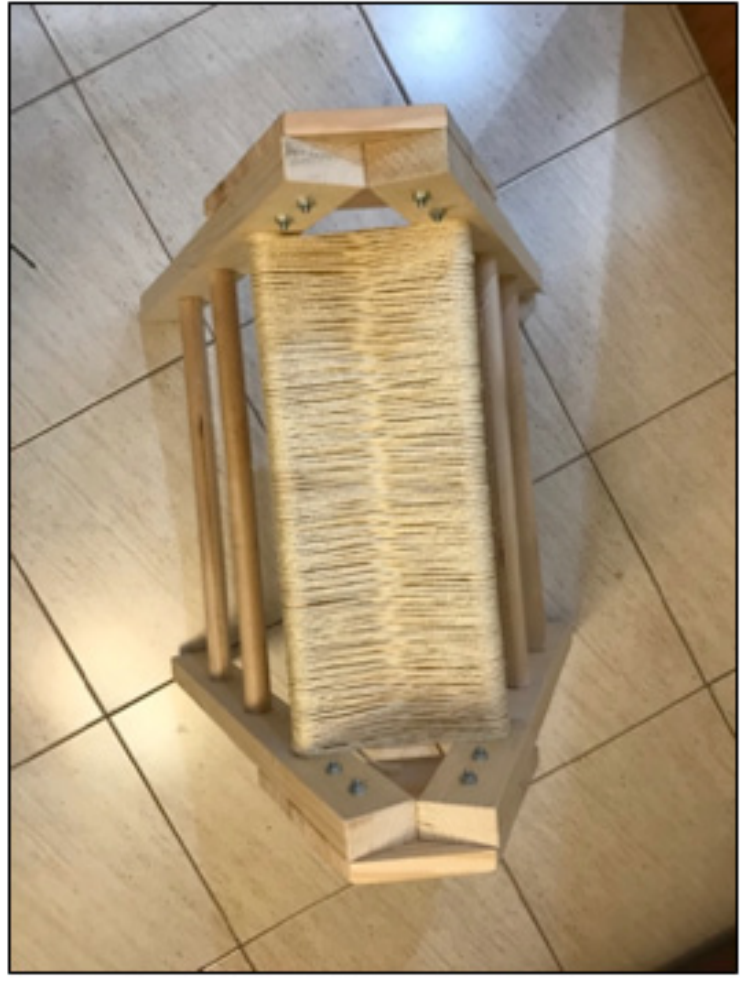

Figura 2 - Perspetiva de cima do Triângulo de Pikler. Fonte: elaboração própria

É considerado um dos materiais mais emblemáticos e identitários da proposta pikleriana, a par do labirinto de Pikler, pela riqueza de explorações e aprendizagens sensoriomotoras que poderá promover, das quais se destacam a perceção e compreensão espacial, nomeadamente a perceção de noções topológicas e de perspetiva; a interação social, que inclui a comunicação não verbal com apoio na interação visual pela troca de olhares entre crianças, a comunicação verbal, e o desenvolvimento autónomo de competências relacionadas com o movimento do corpo e a coordenação motora.

Tal como refere Godall (2016), "o ambiente ideal é uma condição essencial, mas a iniciativa da criança é a chave" (p. 90) e, efetivamente, o Triângulo de Pikler representará um enriquecimento do ambiente, mas é a criança, com a sua iniciativa e liberta das restrições do adulto, que desenvolve a habilidade de agir de forma independente e autónoma através do seu esforço paciente e persistente.

Considerando as premissas pedagógicas de base apresentadas até este ponto, o presente trabalho tem como objetivo descrever e analisar a experimentação do Triângulo de Pikler no âmbito de um estágio desenvolvido em contexto de 
creche, com atenção simultânea aos efeitos desta proposta pedagógica na experiência das crianças e das estagiárias envolvidas.

\section{Método}

\subsection{Participantes e contexto}

O presente trabalho realizou-se no âmbito da unidade curricular (UC) de Prática Educativa Supervisionada I, que integra o plano de estudos do Mestrado em Educação Pré-Escolar de uma instituição de ensino superior portuguesa. Esta UC integra um período de estágio de 140 horas em contexto de creche, acompanhado por processos de supervisão por orientadoras cooperantes e supervisoras da instituição de formação. O estágio, realizado em pares de formação, foi desenvolvido numa instituição privada da Área Metropolitana do Porto, localizada numa zona fortemente urbanizada. A instituição foi construída de raiz, em respeito pela missão educativa e social que desenvolve, abrangendo as valências de creche e de educação pré-escolar. A experiência pikleriana desenvolveu-se numa sala de atividades com um grupo de 12 crianças com idades entre os $12 \mathrm{e}$ os 24 meses, uma educadora de infância, as duas educadoras estagiárias e uma assistente operacional. A sala de atividades caracterizava-se por ter dimensões reduzidas, embora dentro dos limites fixados legalmente. Possuía bastante luz natural e encontrava-se organizada em espaços com uma determinada identidade (e.g., zona de acolhimento, área da casinha), apresentando um espaço central amplo e descongestionado. A sala possuía mobiliário com dimensões adequadas ao tamanho das crianças, e materiais apelativos do ponto de vista sensorial, selecionados com vista ao desenvolvimento da autonomia e da criatividade das crianças. Possuía ainda um espaço exterior exclusivo para as crianças a frequentar a creche.

A experiência partiu da observação diária das necessidades e dos interesses do grupo de crianças, e do seu registo e interpretação à luz de referentes teóricos. Teve como base, também, a preparação prévia e sensibilização das educadoras estagiárias originadas por um estudo realizado de forma minuciosa sobre a perspetiva Pikler. Neste sentido, o presente artigo tem a intenção de partilhar uma experiência de contextualização de uma proposta estudada teoricamente, bem como os saberes que emergiram dessa prática educativa.

\subsection{Instrumentos de recolha de dados}

Os dados foram recolhidos através da observação participante (Estrela, 1990; Mózes, 2016) desenvolvida pelas educadoras estagiárias, bem como das suas notas de campo, que constituíram o diário de bordo de formação profissional. Além 
disso, recorreu-se aos registos fotográficos e audiovisuais realizados quer pelas educadoras estagiárias, quer pela educadora cooperante e assistente operacional da sala. Foram, ainda, utilizados os indicadores de observação do bem-estar e do envolvimento da criança (Laevers et al., 2005) à posteriori, como recurso para análise das fotografias e vídeos registados e apoio à interpretação das experiências das crianças. Para uma melhor compreensão, apresentam-se os referidos indicadores e as grelhas cujo preenchimento serviu de base à interpretação.

\section{Tabela 1. Grelha de observação do bem-estar da criança.}

\begin{tabular}{|c|c|}
\hline \multicolumn{2}{|c|}{$\begin{array}{c}\text { Grelha de observação do bem-estar da criança } \\
\text { Nome da criança: } \\
\text { Data: }\end{array}$} \\
\hline $\begin{array}{l}\text { Indicadores de bem-estar } \\
\text { (Laevers et. al., 2005) }\end{array}$ & $\begin{array}{c}\text { Interpretação com base em evidências } \\
\text { observadas }\end{array}$ \\
\hline $\begin{array}{c}\text { Satisfação } \\
\text { (A criança demonstra prazer, sorri e } \\
\text { expressa felicidade) }\end{array}$ & \\
\hline $\begin{array}{c}\text { Relaxamento e paz interior } \\
\text { (A criança não demonstra tensão ou } \\
\text { inquietação) }\end{array}$ & \\
\hline $\begin{array}{c}\text { Vitalidade } \\
\text { (A criança mostra energia e uma expressão } \\
\text { ativa e leve) }\end{array}$ & \\
\hline $\begin{array}{c}\text { Abertura } \\
\text { (A criança tem uma atitude de abertura } \\
\text { para com o mundo à sua volta, mostra-se } \\
\text { pronta a explorar) }\end{array}$ & \\
\hline $\begin{array}{c}\text { Autoconfiança } \\
\text { (É visível na expressão de orgulho e } \\
\text { assertividade) }\end{array}$ & \\
\hline $\begin{array}{c}\text { Estar em sintonia consigo própria } \\
\text { (A criança não suprime sentimentos e } \\
\text { emoções) }\end{array}$ & \\
\hline
\end{tabular}

Fonte: elaboração própria 
Tabela 2. Grelha de observação do envolvimento da criança.

\begin{tabular}{|c|c|}
\hline \multicolumn{2}{|c|}{ Grelha de observação do envolvimento da criança } \\
Nome da criança: \\
Data:
\end{tabular}

Fonte: elaboração própria 


\section{Procedimentos}

A experiência pikleriana apresentada neste artigo foi realizada com base em princípios e modos operatórios da metodologia de investigação-ação, com respeito pelos processos preconizados por esta metodologia: observação, planificação, ação e reflexão (Latorre, 2008; Máximo-Esteves, 2008). Partiu da observação detalhada do contexto (Bogdan \& Bihlen, 1994) como técnica de recolha de dados, com registo de notas de campo no diário de bordo das educadoras estagiárias. Os processos de observação, direta e participante, focaram os interesses (movimentar o corpo para trepar equipamentos) e necessidades (partilha de espaços e objetos, coordenação motora e equilíbrio) das crianças, bem como a qualidade espácio-material do ambiente educativo, uma vez que somente deste modo é possível agir com intencionalidade educativa, de forma contextualizada e significativa para todos os intervenientes. De facto, a observação constitui um dos procedimentos essenciais para garantir a qualidade da ação profissional (Mózes, 2016), sendo que esta possibilitou a planificação da experiência com a introdução do Triângulo de Pikler. Em reunião de planificação, as educadoras estagiárias propuseram à educadora cooperante este equipamento, que embora não Ihe fosse totalmente desconhecido, nunca fora utilizado na instituição. A proposta foi aceite com alguma curiosidade, uma vez que a profissional tinha interesse em conhecer mais sobre esta pedagogia.

A exploração do material contou com um primeiro momento em grande grupo, em que as educadoras estagiárias iniciaram com a apresentação do Triângulo de Pikler às crianças, colocando-o no centro do tapete. De seguida, as crianças exploraram individualmente o mesmo, contando com a observação e apoio do adulto. É de realçar que não foi explicado previamente de que forma se poderia utilizar este equipamento, de maneira a respeitar a autonomia e a exploração livre das crianças. Após este momento, o Triângulo esteve disponível para as crianças o utilizaram nos seus tempos de brincadeira e jogo livre.

Neste processo foram assegurados cuidados éticos, nomeadamente a autorização para registar em vídeo e fotografia os momentos experienciados, utilizados apenas para análise, interpretação e reflexão no âmbito do processo formativo, e publicadas exclusivamente na plataforma digital ChildDiary, utilizada pela instituição para facilitar a comunicação com famílias e à qual apenas estas têm acesso.

\section{Apresentação e análise dos resultados}

Tomando em consideração os objetivos do presente trabalho, apresentam-se e analisam-se, na presente secção, os principais resultados da experimentação 
do Triângulo de Pikler, considerando-se, em primeiro lugar, a experiência das crianças e, seguidamente, a experiência das educadoras estagiárias envolvidas.

\subsection{Experimentação do Triângulo de Pikler: a experiência das crianças}

Segundo a perspetiva de Pikler-Lóczy, a manipulação, a experimentação ativa, a autonomia e a consideração pelas capacidades motoras da criança são aspetos que devem ser promovidos pelos materiais pedagógicos existentes no ambiente educativo. Desta forma, o Triângulo de Pikler possibilita uma exploração sensoriomotora, centrada nos detalhes e nas características singulares das crianças em contexto, tornando possível melhorar o seu desenvolvimento no que se relaciona com o respeito, o olhar, o gesto, a autonomia, a segurança, o tentar, o experimentar, o parar, o continuar, entre outros (Roso, 2016).

Analisando de modo mais detalhista a experiência das crianças, é de notar que existiram ligeiras diferenças nas suas reações, quando confrontadas com o Triângulo de Pikler.

No primeiro momento de apresentação e exploração individual deste equipamento, a primeira criança fê-lo subindo os degraus de frente e sentando-se na tábua superior, descendo em seguida os degraus com as costas voltadas para o material. Observou-se que as crianças que se seguiram optaram por realizar o movimento que a primeira fez, podendo isto dever-se ao facto de ser um equipamento novo para o grupo e daí terem utilizado a estratégia de imitar o que a primeira realizou. Analisando à luz dos indicadores propostos por Laevers et. al. (2005) foi possível observar sinais de curiosidade, satisfação, abertura à exploração, concentração, energia, visíveis nas suas expressões faciais e posturas. Além disto, é de destacar seis crianças que demonstraram um interesse e envolvimento mais elevado, marcado essencialmente pela sua vitalidade e persistência. Realça-se que houve crianças a demonstrar dificuldades na experimentação do triângulo, manifestando inibição e solicitando o apoio do adulto e, ainda, a existência de uma criança que não explorou o material no decorrer da atividade.

Já no momento de jogo livre do grupo registou-se que algumas crianças revelaram um interesse e vontade elevados em explorar o equipamento assim que este foi colocado à sua disposição e mostraram facilidade em realizar o movimento de subir e descer de forma autónoma. Deste grupo de crianças que exploraram durante o momento de jogo livre, destacaram-se dois grupos, considerando indicadores relativos ao bem-estar e envolvimento (Laevers et. al., 2005) - duas crianças que se envolveram numa atividade intensa prolongada, com sinais de satisfação, autoconfiança, relaxamento e paz interior, concentração, energia, criatividade, persistência e expressão facial e postura; e um grupo constituído 
por cinco crianças que evidenciaram igualmente níveis elevados de bem-estar e envolvimento, por explorarem de forma contínua com momentos de grande intensidade, tendo sido observados os mesmos indicadores que no grupo anterior. Neste grupo de crianças evidenciou-se a destreza de uma das crianças em subir e descer os degraus do material de frente para o mesmo, movimento que ainda nenhuma outra criança tinha realizado. Além disso, destaca-se a atividade de outra criança, uma vez que no momento anterior ao jogo livre esta não explorou o material, passando a fazê-lo de uma forma que evidenciava sinais claros de bem-estar e envolvimento.

Não obstante, ainda neste momento, algumas crianças mostraram-se um pouco mais inseguras e com dificuldade em subir e manter o equilíbrio, solicitando o apoio do adulto. De entre estas, destaca-se uma criança, pela importância que a postura atenta e sensível do adulto teve perante a ação da mesma. 0 episódio que se relata a seguir, surgiu já no momento de jogo livre e em que a criança, apesar de demonstrar interesse em explorar o triângulo, não tomava a iniciativa de o fazer.

"Ao observar a vontade da criança J. em explorar o equipamento, coloqueime à sua altura e questionei-a "J. queres brincar no triângulo?", ao qual a criança respondeu afirmativamente abanando a cabeça. A seguir, a criança aproximou-se do equipamento e colocou o pé no primeiro degrau do mesmo, sendo que eu me mantive presente, com uma postura atenta e apoiante, no decorrer da ação da criança. Contudo, J. não conseguiu encontrar equilíbrio para subir os degraus e, portanto, desceu o pé até ao chão. Olhou para mim com um ar de não saber o que fazer e incentivei "J., tens de fazer força no pé. Vamos lá outra vez, eu ajudo-te.". A criança J. apoiou a mão na lateral do triângulo pikleriano e colocou novamente o pé no primeiro degrau. Evidenciou alguma dificuldade em manter-se equilibrado, mas, com alguma insistência pela minha parte, para que continuasse a fazer força no pé, a criança J. conseguiu subir mais um degrau. Subiu ainda mais um e conseguiu alcançar o topo do triângulo, sentando-se quando aí chegou. A seguir, decidiu sair do equipamento, levantando-se e começando a descer os degraus de frente para as mesmas. Quando colocou, por fim, os pés no chão expressou felicidade com um sorriso e batendo as mãos repetidamente. Alcançou uma vez mais o meu olhar e eu fiz-me acompanhar da sua conquista, batendo as mãos, sorrindo e dizendo "Boa, J. Conseguiste". A seguir, a criança J. decidiu subir uma outra vez o Triângulo de Pikler, mas desta vez de forma autónoma, sem solicitar o apoio do adulto" (Notas de campo da educadora estagiária, dia 08/05/2019).

Após este último segmento, em que foi explicitamente visível a importância que o papel e mão do/a educador/a de infância (Tardos, 2012) tem nos mais 
simples dilemas das crianças, é possível relacionar a sua ação com alguns dos valores e princípios defendidos na pedagogia aqui explorada. Neste sentido, é "reconhecido o papel da educadora de referência ou privilegiada, que é a primeira responsável pelo bem-estar [do grupo] de crianças, e pela relação estável, continuada, autêntica e calorosa dentro da instituição" (Araújo, 2017, p. 106).

De facto, a experiência pikleriana torna evidente a importância que as interações corporais, nomeadamente as mãos, têm no desenvolvimento do bebé e na continuidade da relação rica entre adulto-criança. É deste modo que surge uma metáfora criada nesta experiência intitulada por a mão da educadora, pois nesta é consagrada elevada importância ao modo pelo qual o/a educador/a de infância realiza os movimentos nos momentos de atenção individual (Tardos, 2012). O bem-estar do bebé é proporcionado pela forma como o adulto toca nele, uma vez que uma das grandes fontes de experiências essenciais para o desenvolvimento da criança são as mãos do adulto. Por isto mesmo, no instituto Lóczy e na formação sustentada pela abordagem pikleriana, as/os educadoras/es aprendem a realizar movimentos mais suaves e lentos requeridos nos momentos de dar resposta e oportunidade de participação ao bebé.

Na perspetiva pedagógica de Pikler-Lóczy, "o adulto estimula a atividade das crianças pequenas de maneira indireta e cria as condições para um desenvolvimento equilibrado nos domínios emocional, afetivo, psicomotor e cognitivo" (Falk, 2012, p. 32). Tais condições são conseguidas através de três estratégias como a criação de um ambiente rico, com materiais diversificados ao alcance das crianças, sendo que a escolha dos materiais espelha os gostos das mesmas e as possibilidades de experimentação que esse material oferece; o respeito, por parte do adulto, pelo ritmo das aquisições motoras de cada bebé, tendo sempre em vista o seu bem-estar e autonomia; e a utilização de uma linguagem rica, por parte do/a educador/a, verbal e gestual, que permite à criança desenvolver a consciência de si mesmo e do contexto em que se insere, na medida em que esta se situa nos acontecimentos e nas relações que a afeta. Na experiência relatada, estas estratégias tiveram especial destaque, particularmente no que se refere ao papel do adulto como organizador dos espaços e dos materiais potenciadores de aprendizagem e como apoiante e securizante do desenvolvimento das crianças. Ademais, salienta-se a valorização e o respeito pelo ritmo de desenvolvimento individual de cada criança, bem como a comunicação entre adulto e criança, marcada pela linguagem verbal e não-verbal durante a experimentação do Triângulo de Pikler.

Efetivamente, observa-se nesta perspetiva que as experiências se tornam agradáveis quando vividas nos momentos em que o bebé e o/a educador/a de infância estão numa interação rica, participativa e personalizada e em que o adulto realiza movimentos suaves, doces e interessados - fortalecendo a relação entre 
ambos (Tardos, 2012). Assim sendo, deve-se ter em consideração o tipo de movimentos que se tornam rotineiros e indiferentes, pois, para além de comunicar à criança pequena que o adulto não se encontra motivado e interessado no seu cuidado, impede o desenvolvimento da atividade autónoma da criança, visto que o/a educador/a de infância apenas quer tornar aquele momento o mais rápido e eficaz possível. Na experiência em análise destacou-se a importância dos gestos e movimentos interessados e apoiantes, da mão do/a educador/a, na ação do adulto como andaime (Bruner, 1999) no processo de aprendizagem e desenvolvimento da criança, balanceando o cuidado e o afeto numa postura de humanização.

\subsection{Experimentação do Triângulo de Pikler: a experiência das educadoras estagiárias}

Relativamente à experiência relatada, é importante, também, refletir sobre a influência que esta revelou ter ao nível da aprendizagem profissional das mestrandas, enquanto futuras educadoras de infância.

Um dos aspetos que exigiu, desde logo, uma reflexão cuidada por parte das educadoras estagiárias prendeu-se com a articulação teoria-prática, no sentido da mobilização dos saberes teóricos para a prática pedagógica, mas tendo em atenção as especificidades do contexto. O contexto da sala de atividades onde decorreu a experiência pikleriana não desenvolvia a abordagem pedagógica de Pikler-Lóczy como perspetiva pedagógica adotada pela equipa educativa, o que revelou a necessidade de apropriação e adaptação de conteúdos metodológicopedagógicos no desenvolvimento da atividade.

Ademais, a consciencialização da importância da intencionalidade educativa e do desenvolvimento de propostas que atendam aos interesses e às necessidades das crianças revelou-se crucial para a prática profissional futura, bem como a valorização do papel do/a educador/a de infância na organização do espaço e dos materiais, tendo em conta as características da proposta e do grupo.

O papel do/a educador/a de infância como mediador/a da aprendizagem e do desenvolvimento da criança evidenciou-se uma fonte de aprendizagem para as educadoras estagiárias que, com a experiência em causa, aprenderam a não intervir diretamente na ação da criança e a apoiar quando solicitado, respeitando os ritmos individuais, numa ótica de promoção da autonomia. Pelo exposto, mostrou-se relevante na aprendizagem e desenvolvimento de competências relacionadas com a sensibilidade, a autonomia e a estimulação enquanto futuras profissionais (Bertram \& Pascal, 2009).

O desenvolvimento desta experiência contribuiu, ainda, para a tomada de consciência da importância de escutar e responder às crianças. Dar voz às 
crianças implica uma ação coerente com uma imagem de criança como sujeito autônomo, cooperativo e competente (Fochi, 2018), tal como ficou espelhado na experiência relatada.

A criança foi criando o seu olhar pela organização do espaço, pelo Triângulo de Pikler, pela relação afetiva que promoveu a autonomia, dando-lhe a liberdade de ser a impulsionadora do seu desenvolvimento. Esta experiência fomentou o cuidado amoroso das educadoras estagiárias pelo olhar sensível, pelas palavras e gestos de incentivo, mas ao mesmo tempo, pela liberdade de a criança se desafiar a si própria, que ao subir o triângulo lhe permitiu desenvolver o espírito de iniciativa, o interesse em descobrir o mundo e o prazer da iniciativa autónoma. 0 desejo da criança subir este equipamento dependeu da alegria, da reciprocidade e do sentido de segurança que a criança experimentou numa "elaboração de uma verdadeira coreografia de como o adulto deve agir" (Tardos, 2013, p.1). E aqui a mão das educadoras estagiárias incentivou a exploração destes estímulos táteis e de sentimento de pertença.

Esta consciencialização coloca em evidência a importância de que atuar na educação em contexto de creche exige um saber específico sobre as características da primeira infância - fase da vida que é tão própria e complexa - e um conhecimento detalhado a nível pedagógico e metodológico.

\section{Considerações finais}

Considerando de forma próxima a experimentação do Triângulo de Pikler, ficou explícita a importância desta proposta pikleriana na experiência da criança e no percurso de formação inicial das educadoras estagiárias. Se na primeira a perspetiva pedagógica pikleriana evidenciou promover a autonomia, a atenção, a expressão sensório motora, a curiosidade e as interações, também esta teve impacto no desenvolvimento profissional das mestrandas, atribuindo significado à ação desenvolvida na prática educativa supervisionada. De salientar, ainda, que os olhares cúmplices de ajuda e apoio se mostraram essenciais e relevantes no processo desenvolvimental, assim como a mão das estagiárias contribuiu para a segurança e confiança das crianças.

Destaca-se que emergiram algumas dificuldades que exigiram um trabalho de pesquisa e de conceção do equipamento - Triângulo de Pikler - na opção de materiais (madeira e corda) e no seu manuseamento, sendo necessário recorrer a outros intervenientes para a sua construção e intersetando saberes teóricos e outros saberes práticos. Ademais, uma vez que a pedagogia pikleriana era novidade na ação pedagógica da instituição cooperante, tornou-se imprescindível o trabalho de e em equipa com os demais agentes educativos, bem como se demonstrou visível a importância da formação contínua e da aprendizagem ao 
longo da vida. Neste sentido, às educadoras estagiárias, cujo estágio é a primeira socialização profissional, permitiu-Ihes um olhar formativo que emergiu da investigação e da transformação da ação, que, por sua vez, Ihes possibilitou, a partir de bases teóricas sobre a perspetiva pikleriana, criar oportunidades para outra forma de brincar. E através da outra forma de brincar pelo Triângulo de Pikler construíram o saber de futuras profissionais pela "[...] exigência a que não se pode renunciar, pois a infância é um período da realização afetiva, intelectual, sócio relacional e intercultural de grande impacto no processo de humanização" (Oliveira-Formosinho, 2001, p. 87). O saber profissional assemelha-se a uma janela de compreensão e de apropriação, em que os espaços educativos são laboratórios de vida das crianças e dos profissionais onde todos aprendem e se formam pela procura de inovação numa "interface entre a prática e a teoria" (Araújo, 2017, p. 104). Salientam-se, assim, os tempos de investigar e de formar na prática que apoiaram as educadoras estagiárias e a educadora de infância. A formação permanente é prática regular na perspetiva pikleriana, onde os detalhes e a sua análise permitem narrar o saber da sua experiência entre os profissionais em formação inicial e/ou contínua, atribuindo valor ao processo, aos ritmos de desenvolvimento e, por conseguinte, a uma (re)organização dos espaços, dos materiais e à (re)construção da relação criança-educador/a de infância.

A experiência pikleriana foi vivida numa dinâmica colaborativa entre a equipa pedagógica, através de uma atitude reflexiva, experiencial e social e na procura de proximidades, pois educar uma criança implica ser continuamente desafiado a melhorar a ação educativa. A mesma teve repercussões na vivência das crianças ao nível das emoções, das interações e da expressão sensório-motora, e no percurso formativo das educadoras estagiárias, provocando a construção de disposições pessoais e competências profissionais que são elementares para desenvolver ações com crianças no contexto de creche.

\section{Notas}

Este trabalho foi financiado por fundos nacionais através da FCT - Fundação para a Ciência e a Tecnologia, I.P., no âmbito do projeto UIDB/05198/2020 (Centro de Investigação e Inovação em Educação, inED)

\section{Referencias bibliográficas}

Araújo, S. (2017). Perspetivas pedagógicas para a educação em creche: princípios convergentes e implicações para a prática. Cadernos de Educação de Infância, 112, 104-112.

Bakhurst, D., \& Shanker, S. G. (Eds.) (2001). Jerome Bruner: Language, culture and self. Sage Publications.
Bertram, T., \& Pascal, C. (2009). Desenvolvendo a Qualidade em Parcerias - Estudos de caso.

Ministério da Educação.

Bogdan, R., \& Biklen, S. (1994). Investigação qualitativa em educação - Uma introdução à teoria e aos métodos. Porto Editora. 
Bruner, J. (1999). Para uma teoria da Educação. Relógio D’Água Editores.

David, M., \& Appell, G. (2010). Lóçy, una insólita atención personal (3. ${ }^{\mathrm{a}} \mathrm{ed}$.). Octaedro Editora.

El «Laberinto» Pikler (s.d.). Pikler-Lóczy: Eusksal Herriko Elkartea. https:/ / url.gratis/ GIHdx.

Estrela, A. (1990). Teoria e prática de observação de classes: Uma estratégia de formação de professores. Instituto de Investigação Científica.

Falk, J. (2012). La estabilidad para la continuidad y calidad de las atenciones y las relaciones. En J. Falk (ed.), Lócayy, educación infantil (pp. 21-34). Octaedro.

Fochi, P. (2018). Pikler-Lóczy: A construção de uma pedagogia dos detalhes. In J. OliveiraFormosinho \& S. Barros Araújo (Orgs.), Modelos pedagógicos para a educação em creche (pp.181-195). Porto Editora.

Fochi, P. S., Drechsler, C. F., Foesten, P., \& Cavalheiro, C. (2017). A pedagogia dos detalhes para o trabalho com bebês na creche a partirdos pressupostos de Lóczy.Olh@res, 5(1), 35-49. https://url.gratis/FX1kw.

Formosinho, J. (2013). A perspetiva educativa da associação Criança: Pedagogia-em-

Participação. In J. Oliveira-Formosinho (Org.), Modelos curriculares para a Educação de Infância - Construindo uma práxis de participação (pp. 2654). Porto Editora.

Godall, T. (2016). Movimiento libre y entornos óptimos. Reflexiones a partir de un estudio com bebés. RELADEI - Revista Latinoamericana de Educación Infantil, 5(3), 79-90. https://url.gratis/BsBQt.

Kálló, V., \& Vámos, J. (2014). Iniciativa, cooperação e reciprocidade - $O$ tempo do bebé (2): O banho e o cuidado [DVD]. Budapeste: Associação Pikler-Lóczy da Hungria.

Laevers, F. (Ed.), Daems, M., Debruyckere, G., Declercq, B., Moons, J., Silkens, K., Snoeck, G.,
\& Van Kessel, M. (2005). SiCs [ZiCo] - Wellbeing and involvement in care: A process oriented selfevaluation instrument for care settings - Manual. Kind \& Gezin and Research Centre for Experiential Education - University of Leuven.

Latorre, A. (2008). La investigación-acción. Conocer y cambiar la práctica educativa. Editorial Graó.

Máximo-Esteves, L. (2008). Visão panorâmica da investigação-ação. Porto Editora.

Mózes, E. (2016). La observacion en la Pedagogia PikLer. RELADEI - Revista Latinoamericana de Educación Infantil, 5(3), 27-35. https://url.gratis/HUhVC.

Oliveira-Formosinho, J. (2001). A profissionalidade específica da educação de infância e os estilos de interacção adulto/ criança. In J. Oliveira-Formosinho \& J. Formosinho (Orgs.), Associação Criança: um contexto de formação em contexto (pp. 80-103). Livraria Minho.

Oliveira-Formosinho, J., \& Araújo, S. B. (Orgs.) (2018). Modelos pedagógicos para a educação em creche. Porto Editora.

Roso, C. A. (2016). Sobre el equipamiento Pikler. RELADEI - Revista Latinoamericana de Educación Infantil, 5(3), 126-128. https:/ / url. gratis/aL60h.

Szoke, A. (2016). Autónomo, pero no abandonado a su suerte. El apoyo de la actividade autónoma en la escuela infantil 0-3. RELADEI - Revista Latinoamericana de Educación Infantil, 5(3), 41-46. https://url. gratis/UtDYO.

Tardos, A. (2012). La mano de la educadora. In J. Falk (ed.), Lóczyy, educación infantil (pp. 5968). Octaedro.

Tardos, A. (2013). A herdeira de Lóczy. Revista Educação Infantil. https:/ / abebe.zohosites. com/files/A-herdeira-de-L \%C3\%B3czy.pdf Tardos, A., \& Appell, G. (2013). A atenção do bebé ao brincar [DVD]. Budapeste: Associação Pikler-Lóczy da Hungria. 